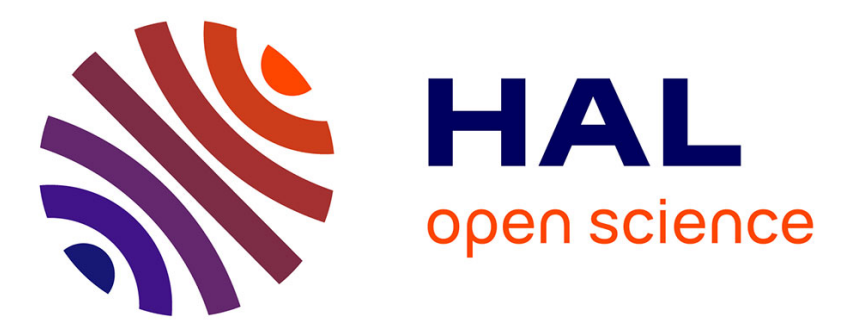

\title{
Antidepressant utilization patterns and mortality in Swedish men and women aged 20-34 years
}

Karolina Andersson Sundell, Mika Gissler, Max Petzold, Margda Waern

\section{To cite this version:}

Karolina Andersson Sundell, Mika Gissler, Max Petzold, Margda Waern. Antidepressant utilization patterns and mortality in Swedish men and women aged 20-34 years. European Journal of Clinical Pharmacology, 2010, 67 (2), pp.169-178. 10.1007/s00228-010-0933-z . hal-00639776

\section{HAL Id: hal-00639776 https://hal.science/hal-00639776}

Submitted on 10 Nov 2011

HAL is a multi-disciplinary open access archive for the deposit and dissemination of scientific research documents, whether they are published or not. The documents may come from teaching and research institutions in France or abroad, or from public or private research centers.
L'archive ouverte pluridisciplinaire HAL, est destinée au dépôt et à la diffusion de documents scientifiques de niveau recherche, publiés ou non, émanant des établissements d'enseignement et de recherche français ou étrangers, des laboratoires publics ou privés. 


\title{
Antidepressant utilization patterns and mortality in Swedish men and women aged 20-34 years
}

\author{
Karolina Andersson Sundell MPharmSc, PhD ${ }^{1 *}$, Mika Gissler MSocSc, PhD ${ }^{1,2}$, Max Petzold PhD ${ }^{1}$, \\ Margda Waern MD, PhD ${ }^{3}$ \\ ${ }^{1}$ Nordic School of Public Health, PO Box 12133, SE 40242 Gothenburg, Sweden \\ ${ }^{2}$ National Institute for Health and Welfare, P.O. Box 30, FI-00271 Helsinki, Finland \\ ${ }^{3}$ Psychiatry and Neurochemistry, Institute of Neuroscience and Physiology, University of Gothenburg, \\ Department of psychiatry, Sahlgrenska university hospital, SE 41315 Gothenburg, Sweden \\ *Corresponding author: Karolina Andersson Sundell \\ e-mail: karolina.a.sundell@nhv.se
}

Phone: +4631 693927, Fax: +4631691777 


\section{Abstract}

Purpose

To compare antidepressant utilization patterns and mortality in relation to antidepressant use in men and women aged $20-34$ years.

Methods

We used data from the Swedish Prescribed Drug Register to identify adults aged 20-34 years who purchased at least one antidepressant in 2006. Information on death and migration was obtained from the Total Population Register by record linkage. One-year prevalence and proportion of new users, amount of purchased antidepressants, concurrent use of other antidepressants, mood stabilizers and antipsychotics as well as mortality was assessed.

Results

The one-year prevalence of antidepressant use was higher among women than men $(7.2 \%$ vs. $4.0 \%, p<0.001)$, being $5.6 \%$ among all Swedes aged $20-34$ years $(n=94,239)$. SSRIs dominated at baseline, more common among women than men $(78.7 \%$ vs. $71.7 \%, p<0.001)$. Of the new users, $22.3 \%$ filled only one prescription during the study period, men more often than women ( $24.1 \%$ vs. $21.4 \%, p<0.001)$. The mortality rate was higher in men than in women ( 24 vs. 14 per 10,000, p=0.009). Concurrent use of mood stabilizers (48 vs. 16 per 10,000, $p<0.001$ ) and antipsychotics ( 50 vs. 14 per 10,000, $p<0.001$ ) was associated with increased mortality in men and women.

Conclusions

Almost twice as many Swedish women than men aged 20-34 years purchased antidepressants in 2006. Differences in utilization patterns between sexes were rather small. Discontinuation rates were high, indicating that increased awareness on attitudes to treatment is needed. In both sexes, mortality rates were elevated among those concurrently using mood stabilizers and antipsychotics which need further investigation.

Key words: utilization, antidepressants, young adults, mood stabilisers, mortality, Swedish Prescribed Drug Register 


\section{Introduction}

By the year 2020, depression is expected to constitute the second largest source of global burden of disease after heart disease [1]. Consequences of depression for the individual and for the society include lowered quality of life, social isolation, decreased intellectual capacity, inability to carry out activities of daily living, increased health care costs, increased need for institutionalised care and increased risk of suicide [2-5]. Full remission from depression with antidepressant treatment is associated with significant improvements in health-related quality of life, as well as significant and economically important reductions in health care costs [6].

The reported prevalence of antidepressant use in the general population varies between $4 \%$ and 13\% [7-11]. Figures are higher among females than males and increase with age [7, 11]. Gender differences in patterns of use have been reported, e.g. a larger proportion of the women received tricyclic antidepressants compared to men and women were more likely to continue treatment during at least six months [9]. Previous studies have reported that $15-35 \%$ of those initiating antidepressant treatments discontinue within one or two months.

Discontinuation was more common in groups with low education, low income, unemployment and foreign citizenship [9, 11-13]. Van Geffen et al. reported that the majority of those that discontinued antidepressant treatment did not inform their physician about their decision [13]. This indicates a considerable information gap between patients and physicians and substantial problems for these patients potentially leading to relapse. Regarding antidepressant use and mortality, results are mixed. Some report increased rates of mortality and suicide in particular, $[10,14,15]$, among antidepressant users whereas others do not [16, 17]. None of these studied mortality in young adults specifically. 
The number of sick-listings and disability pensions related to mental ill-health has increased in Sweden, especially among young adults aged 35 years and less [18]. We were therefore interested in investigating utilization patterns of antidepressants in this age group. The aim of this study was to compare utilization of antidepressants in 20-34 year old men and women in a total national database. Further, we wanted to examine mortality rates in relation to utilization pattern.

\section{Methods}

\section{Study population and study period}

The study population encompassed all Swedish residents aged 20-34 years in 2006 $(\mathrm{n}=1,691,356)$. The study period ranged from January 1, 2006 until December 31, 2006.

\section{Data on purchased medicines}

The Swedish Prescribed Drug Register, encompassing all prescribed medicines dispensed in Swedish pharmacies since July 1, 2005, was used to identify persons who filled at least one antidepressant prescription at a Swedish pharmacy between July 1, 2005 and December 31, 2006 [19]. The register contains information regarding each dispensed drug, the unique personal identification number of the person for whom the drug was prescribed and the date of purchase. Medicines are included in the register irrespective of whether they are encompassed by the Swedish Pharmaceutical Benefits Scheme or not, but the register does not cover medicines provided during in-patient care. Drugs are coded according to the Anatomical Therapeutic Chemical (ATC) system [20]. The Swedish Prescribed Drug Register includes information about substance, ATC-code, package size, number of packages and number of defined daily doses (DDD) for each dispensed drug. Antidepressants were defined 
as all drugs in the ATC-group N06A. The register also specifies whether the purchase concerned a standard prescription or a multi-dose dispensed drug. Within the Swedish Pharmaceutical Benefits Scheme, 90 days supply of prescription drugs can be dispensed at each occasion [21]. The database distinguishes between standard prescriptions and medicines dispensed within the multi-dose drug dispensary system. Users of multi-dose dispensed drugs collect their medicines more frequently, usually every second week.

Ethics approval, which was a prerequisite for data access, was obtained from the regional ethics board in Gothenburg.

\section{Measures}

For each individual, index date was defined as the date of the first purchase of an antidepressant in 2006. One-year prevalence was defined as the proportion of the total population aged 20-34 years (as of December 31, 2006) that purchased at least one antidepressant during 2006. We defined new users as individuals who purchased an antidepressant in 2006 who had filled no antidepressant prescriptions between July 1 and December 31, 2005.

The number of filled antidepressant prescriptions per person was investigated for the year 2006 for new users. New users were in this analysis restricted to those who filled their first antidepressant prescription between January 1 and June 30, 2006. Those utilising the multidose system were excluded since they show an artificially regular pattern. Purchases of start packages ( $\leq 32$ tablets or capsules per package) at index date were also assessed. The number of doses per filled prescription was calculated for both all users and new users, based on number of tablets/capsules. Separate calculations were made for those utilizing the multi-dose 
system. Total number of doses dispensed during the study period was calculated for each individual.

Concurrent use of SSRIs, venlafaxine and mirtazapine was assessed among new users as was switching between antidepressant types. Concurrent use was defined as purchases of two or more of these within a 125 day period. Switching was defined as non-concurrent use of the specified antidepressants. The time frame of 125 days was chosen to correspond with the Swedish pharmaceutical benefits scheme [21], where in practice packages for 100 days often are dispensed instead of 90 days due to package sizes of 98 or 100 units. Allowing an adherence of at least 80 percent, one filled prescription would last for a maximum of 125 days.

Use of mood stabilizers was defined as one or more purchase of lithium, carbamazepine, lamotrigine or valproic acid during the study period. Concurrent use of mood stabilizers was assessed among all antidepressant users during the study period. Concurrent use of antipsychotics (N05A) was also assessed.

\section{Data on death and migration}

Information about date of death and migration in 2006 was obtained by record linkage to the Total Population Register using the unique personal identification number available for all Swedish citizens and permanent residents. Mortality rates were calculated per 10,000 inhabitants. In total, 166 persons died and 592 migrated during the study period $(0.2 \%$ and $0.6 \%$ of the antidepressant users, respectively). These persons were omitted from the description of the number of filled antidepressant prescriptions per individual and switching and concurrent use of other antidepressants. 
To assess whether the individual theoretically had enough antidepressant medication at the time of death assuming full adherence, the dispensing records of the last dispensed prescription were reviewed for those who died. The prescribed dose as stated in the dosage text was used as the consumption rate. If the dispensed amount was insufficient to cover the entire time period, the number of months that had elapsed from the last theoretical dose until date of death was recorded.

\section{Statistical analysis}

Data management and statistical analyses were performed using SAS version 9.1.3 (SAS Institute, NC) and Stata version 10.1 (StataCorp, TX). Pearson $\chi^{2}$ - test and Fisher's exact test were used to analyse differences in proportions, and Student's t-test was used to analyse differences between means. Differences in proportions were calculated and presented as risk ratios, RR, with $95 \%$ confidence intervals. Risk ratios for mortality were calculated stratified by sex, but no age-adjustment was made due to the rather short age interval. The level for statistical significance was 0.05 .

\section{Results}

During 2006, 94,239 Swedes aged 20-34 years (34,472 men and 59,750 women) purchased at least one antidepressant, corresponding to a one-year prevalence of 5.6\%. Prevalence was higher among women compared to men and increased with age $(\mathrm{p}<0.001)($ Table 1$)$. Four out of ten were new users (Table 1). 
Altogether, $2.5 \%$ of the antidepressant users $(n=2,335)$ had multi-dose dispensed drugs. Multi-dose dispensed drugs was more frequent among male users than among female users (3.3\% vs. $2.0 \% \mathrm{p}<0.001)$.

\section{Type of antidepressants purchased}

Table 2 shows the distribution of different antidepressant substances at baseline for all users by sex. Selective serotonin inhibitors (SSRIs) dominated at baseline; citalopram (28\%) and sertraline $(24 \%)$ were the most common substances. Mirtazapine was more than twice as frequent in men compared to women (RR 2.22) whereas fluoxetine was almost twice as common among women than among men (RR 1.70) (Table 2).

The proportion of tricyclic antidepressants (TCA) increased by age for both men and women (men $4.7 \%$ for $20-24$ years, $6.2 \%$ for $25-29$ years, $8.5 \%$ for $30-34$ years, $\mathrm{p}<0.001$; women $3.9 \%, 5.3 \%$ and $7.5 \%$ respectively, $\mathrm{p}<0.001)$ whereas the proportion of SSRIs declined by age (men $74.6 \%, 71.3 \%$ and $70.6 \%$ respectively, $\mathrm{p}<0.001$; women $81.4 \%, 79.3 \%$ and $76.6 \%$ respectively, $\mathrm{p}<0.001)$. This was consistent in both men and women and also among new users. No such patterns were found for monoamino-oxidase A inhibitors. For the group other antidepressants, there was a slightly increasing trend by age for men $(0.7 \%, 0.8 \%$ and $1.0 \%$ respectively, $\mathrm{p}=0.014)$, but not for women.

\section{Amounts of antidepressants purchased}

The average number of doses purchased per filled prescription (tablets/capsules excluding solution) was lower among new users compared to those who purchased antidepressants in both 2005 and 2006 (63.4 vs. 79.8, p<0.001). The average number of doses purchased was 
similar for male and female users. After exclusion of multi-dose users, the average number of doses increased from 77.5 (median 98) to 85.4 (median 98).

Among new users who purchased their first antidepressant in the first six months of 2006 $(n=21,199)$, the mean number of filled prescriptions was 3.8 (median 3.0) during the study period for those purchasing prescriptions. There were no relevant differences between men and women in average number of filled prescriptions. Over one-fifth $(22.3 \%)$ filled only one prescription; this proportion was somewhat higher among males than females $(24.1 \%$ vs. 21.4\%, $\mathrm{p}<0.001$ ) (Table 3). A lower proportion of those filling only one prescription purchased a start package at index date compared to those that filled several prescriptions (48.2\% vs. $62.3 \%, \mathrm{p}<0.001)$, this difference was consistent among both men and women when analysed separately. Among new users, the average number of doses purchased from index date until end of study period was higher among those who did not purchase a start package compared to those who did (298 vs. $250, \mathrm{p}<0.001)$.

Among those who filled one prescription only, a higher proportion of the men had purchased a start package compared to the women $(51.1 \%$ vs. $46.3 \%, \mathrm{p}=0.001)$. Furthermore, the proportion of start packages differed between the different types of antidepressants (TCA 21.5\%; SSRI 49.0\%; other antidepressants $72.7 \%, \mathrm{p}<0.001$ ). This was consistent among both men and women when analysed separately. The proportion of individuals that filled only one prescription differed by substance at index date and sex (Table 4). The proportion was higher among men than women for escitalopram, whereas the reverse was observed for duloxetine. 


\section{Concurrent use and switching}

A higher proportion of those that started on SSRIs switched to or concurrently used mirtazapine $(0.5 \% ; 4.8 \%)$ compared to venlafaxine $(0.2 \% ; 3.1 \%)(\mathrm{p}<0.001)$. A similar pattern was seen among those that started on mirtazapine, a higher proportion switched to or concurrently used SSRIs $(2.7 \% ; 18.0 \%)$ compared to venlafaxine $(0.3 \% ; 4.9 \%)(\mathrm{p}<0.001)$. Among those starting on venlafaxine, rate of switching to SSRIs and mirtazapine was similar $(1.2 \%$ vs. $0.6 \%)(p=0.132)$. Among those starting with venlafaxine, the proportion of concurrent use with SSRI was higher compared to concurrent use with mirtazapine $(8.2 \%$ vs. $5.0 \%)(\mathrm{p}=0.006)$.

\section{Concurrent use of mood stabilizing medicines and antipsychotics}

About $1.1 \%$ of those that purchased an antidepressant during 2006 also filled a prescription for lithium $(n=995)$. There was no sex difference ( $1.1 \%$ men vs. $1.0 \%$ women, $p=0.643)$. In total, $3.8 \%$ of the antidepressant users $(n=3,559)$ also purchased a mood stabilizer (carbamazepine, valproic acid or lamotrigine). The proportion was higher among men than women $(4.1 \%$ vs. $3.6 \%, \mathrm{p}<0.001)$.

In total, $9.6 \%$ of the antidepressant users $(n=9,065)$ also used an antipsychotic agent. A mood stabilizer was used in 349 of the antidepressant users who also purchased an antipsychotic agent. The proportion concurrent use of antipsychotics was higher among men than women $(12.7 \%$ vs. $7.9 \%, \mathrm{p}<0.001)$. 


\section{Mortality rates}

Table 5 shows mortality rates and risk ratios by utilization pattern. The mortality rate for all antidepressant users was significantly higher among men than women (23.5 vs. 14.2 per 10,000 inhabitants, $\mathrm{p}=0.009$ ). The risk ratio was higher among antidepressant users than among non-users. This was also the case for those utilizing the multi-dose system compared to those with prescriptions (Table 5).

Mortality was increased among antidepressant users who purchased carbamazepine, lamotrigine or valproic acid compared to those who did not (RR 2.95 (95\% CI 1.59-5.47)). This was not the case for lithium. The mortality rate was also elevated among antidepressant users who filled at least one antipsychotic prescription during the study period (RR 2.83 (95\% CI 2.20-3.63)). We observed somewhat more pronounced differences in risk ratios among women for several of the comparisons whereas the differences were somewhat attenuated for men. There were, however, exceptions (Table 5).

Among those who died, a majority $(72.3 \%)$ theoretically had antidepressants available at the date of death. This was consistent also in the subgroup who were new users (74.2\%). Among new users who had filled one prescription only, 58.9\% theoretically had antidepressants available at the time of death whereas the corresponding proportion for those filling two or more prescriptions was $79.1 \%$. For those who theoretically had finished treatment before death, the median time that elapsed from the end of treatment until death was 1.75 months (inter-quartile range 4.25 ). In $47.7 \%$ of these, the time between theoretical end date and death was a month or less. 


\section{Discussion}

One out of 18 adults aged 20-34 years in Sweden purchased antidepressants in 2006 and almost half of these were new users. About twice as many women as men aged 20-34 years filled at least one antidepressant prescription. The discontinuation rate was high and slightly elevated in men. Mortality was higher among users and further elevated among early discontinuers. Further, those who also used mood stabilizers or antipsychotics had elevated mortality. This was not found for those who concurrently used lithium. We observed that the mortality rate was higher among men than women, but the risk ratios associated with death were somewhat more elevated among women than men.

The one-year prevalence of purchased antidepressants in this study was slightly higher than earlier studies of younger adults in other settings and somewhat different age groups [7, 11, 22]. Antidepressant sales have steadily increased over the last decades, thus the level of use varies with the time when the measurement was conducted [22, 23].

Citalopram and sertraline were the most prominently prescribed substances at baseline followed by venlafaxine and mirtazapine. This finding differs somewhat from those reported from studies conducted in other settings [11, 13, 22, 24, 25]. For example, recent Dutch and Italian studies have reported paroxetine to be the most commonly used substance followed by citalopram [11, 13]. The black box warnings concerning antidepressants and emerging suicidality in young people might have affected the prescribing patterns in this age group. Sex differences in utilization patterns were in accordance with earlier research [11, 25].

Our finding that one-fifth filled only one prescription is in line with previously reported early discontinuation rates $[9,11-13]$. Previous studies have also reported variation in early 
discontinuation rates by antidepressant type [12, 13], although differences were even more pronounced in our study. This could be due to differences in size of the examined population, time windows as well as variations in prescription patterns. Furthermore, the results in this study suggested that the use of start packages might help to prevent early discontinuation. It is possible that those receiving start packages for the first filled prescription of antidepressants are more closely monitored or differ in other aspects. We also found that the total amount of purchased medication was lower among those who purchased a start package at index date which somewhat contradicts the notion that start packages might prevent early discontinuation. Our data do not allow for in depth investigation which would require assessment of each individual's theoretical pattern of use including time exposed taking indication into account during a longer observation period. In a six-month follow up of selfreported depression symptoms, van Geffen et al. reported that those that never filled their prescriptions had lower severity of depression at baseline [13]. Severity of depression decreased in both continuers and discontinuers over time in that study, which might reflect the natural course of the depression. There could be some situations in which the physician prescribed an antidepressant, without discussing treatment preferences with the patient which might contribute to non-adherence.

We found increased mortality rates for young adults in Sweden who purchased antidepressants compared to those who did not. Previous studies have shown conflicting results. Some report increased mortality among antidepressant users [10], whereas others report the opposite [26]. This study only encompasses data for one and a half years and a young population. The number of deaths was low, and our findings should be interpreted with caution. We did not have access to cause-of-death data, nor could we control for potential confounding factors such as co-morbidity and confounding by indication. There are many 
factors that contribute to increased mortality. Although we could not control for potential confounding; we have tried to include some aspects e.g. concurrent use of antipsychotics and mood stabilisers. Our study design did not allow any attributions of mortality, but our findings indicate that it is important to take utilization patterns such as length of treatment, type of antidepressant and concurrent drug use into account when analysing mortality risk, as has been shown earlier in relation to suicide [27, 28] and suicide attempt [15]. We found elevated mortality rates among new users filling one antidepressant prescription only; this is influenced by the fact that one cannot fill another prescription after death. Therefore, those dying in the study period are likely to have filled fewer prescriptions compared to the survivors due to shorter follow-up time.

To the best of our knowledge, this is the first study to demonstrate elevated mortality rates among young adults with concomitant use of anticonvulsant mood stabilizers. No increase in mortality could be shown for concurrent lithium users. Recent studies encompassing mixed age adult populations have reported higher mortality rates and slightly elevated suicide rates among users of anticonvulsant mood stabilizers compared to lithium users [29-31]. According to the authors, part of the difference was explained by the fact that anticonvulsant users were older than lithium users [29]. Another consideration is that lithium users may be more closely monitored because of the potential for serious adverse side effects. Further studies with longer follow-up periods and more background variables and diagnostic information are needed to investigate mortality risks and patterns more closely.

\section{Strengths and limitations}

As mentioned earlier the Swedish Prescribed Drug Register includes all dispensed medicines from July 1, 2005 independent of reimbursement status [19]. While persons who filled a single 
antidepressant prescription prior to hospitalization would be misclassified as discontinuers, they would need new medicines after discharge, so this is unlikely to alter the results. A longer study period and linkage to the hospital inpatient register would be needed to shed further light on this. This would also allow for confounding by indication to some extent. In order to investigate whether there were differences in amounts between those purchasing a start package and those who did not, the total amount of antidepressants was calculated for each individual. The theoretical length of treatment periods, however, could not be assessed due to the short study period and the non-standardised dosage information. Another limitation concerns the lack of data regarding treatment setting. Persistence has been reported to be higher among patients that received their first antidepressant prescription from a psychiatrist compared to those that received their first prescription from a general practitioner [32].

The short run-in period was necessitated by the fact that the Swedish Prescribed Drug Register was newly established when the study was initiated which might have affected the results. The comparably short run-in period, and older data as well as a young age group may help to explain the considerably higher proportion of new users found in this study compared to other studies [9]. Garđarsdóttir et al. [33], however, showed that the differences in incidence when the run-in period was increased from six to twelve months were smaller for the age group 18-30 years than for the older age groups.

A further limitation is that the register lacks standardised data on indication and dosage. Therefore, we could not distinguish between patients that received antidepressants for treatment of depression nor bipolar disorders or depression with psychotic characteristics versus treatment of other psychiatric conditions. This may have implications on recommended length of treatment period and also on expected therapeutic response, since bipolar disorder 
and major depression with psychotic symptoms might be recalcitrant to treatment. However, previous studies have reported that depression is the most common indication for antidepressants in outpatient care followed by anxiety/panic disorders $[34,35]$. Finally, the register is based on purchases, and there is no information regarding adherence, nor is there any information regarding other forms of medical and psychological treatments.

\section{Conclusion}

Although twice as many women compared to men purchased antidepressants there were rather small differences in patterns of use. Mortality rates were higher among male users compared to female users and associated with treatment discontinuation, but the number of deaths was low. The finding that mortality rates were particularly high among the young adults in our study population who were on augmentation treatment with mood stabilizers but not elevated for those on lithium calls for further study. Discussion about patients' attitudes to medicine use and intensified support during treatment initiation should be considered in order to decrease the discontinuation rate.

Acknowledgements

Data collection was supported in part by a post doc scholarship from the Swedish Lundbeck foundation. The study was also financed with internal funds. The authors declare that they have no conflict of interest. 


\section{References}

1. Murray CJ, Lopez AD (1997) Alternative projections of mortality and disability by cause 1990-2020: Global Burden of Disease Study. Lancet. doi: 10.1016/S0140-6736(96)07492-2

2. Pollack MH (2005) Comorbid anxiety and depression. J Clin Psychiatry 66 Suppl 8:22-9

3. Simon NM (2009) Generalized anxiety disorder and psychiatric comorbidities such as depression, bipolar disorder, and substance abuse. J Clin Psychiatry 70 Suppl 2:10-14

4. Sobocki P, Ekman M, Agren H, Krakau I, Runeson B, Martensson B, Jonsson B (2007) Health-related quality of life measured with EQ-5D in patients treated for depression in primary care. Value Health. doi: 10.1111/j.15244733.2006.00162.x

5. Sobocki P, Lekander I, Borgstrom F, Strom O, Runeson B (2007) The economic burden of depression in Sweden from 1997 to 2005. Eur Psychiatry. doi: 10.1016/j.eurpsy.2006.10.006

6. Sobocki P, Ekman M, Agren H, Runeson B, Jonsson B (2006) The mission is remission: health economic consequences of achieving full remission with antidepressant treatment for depression. Int J Clin Pract. doi: 10.1111/j.1742-1241.2006.00997.x

7. Beck CA, Patten SB, Williams JV, Wang JL, Currie SR, Maxwell CJ, El-Guebaly N (2005) Antidepressant utilization in Canada. Soc Psychiatry Psychiatr Epidemiol 40:799-807

8. Henriksson S, Asplund R, Boethius G, Hallstrom T, Isacsson G (2006) Infrequent use of antidepressants in depressed individuals (an interview and prescription database study in a defined Swedish population 20012002). Eur Psychiatry. doi: 10.1016/j.eurpsy.2006.04.003

9. Isacsson G, Boethius G, Henriksson S, Jones JK, Bergman U (1999) Selective serotonin reuptake inhibitors have broadened the utilisation of antidepressant treatment in accordance with recommendations. Findings from a Swedish prescription database. J Affect Disord 53:15-22

10. Kivimaki M, Gunnell D, Lawlor DA, Davey Smith G, Pentti J, Virtanen M, Elovainio M, Klaukka T, Vahtera J (2007) Social inequalities in antidepressant treatment and mortality: a longitudinal register study. Psychol Med. doi: 10.1017/S0033291706009457

11. Percudani M, Barbui C, Fortino I, Petrovich L (2004) Antidepressant drug use in Lombardy, Italy: a population-based study. J Affect Disord. doi: 10.1016/j.jad.2004.07.005

12. Hansen DG, Vach W, Rosholm JU, Sondergaard J, Gram LF, Kragstrup J (2004) Early discontinuation of antidepressants in general practice: association with patient and prescriber characteristics. Fam Pract 21:623-9

13. van Geffen EC, van Hulten R, Bouvy ML, Egberts AC, Heerdink ER (2008) Characteristics and reasons associated with nonacceptance of selective serotonin-reuptake inhibitor treatment. Ann Pharmacother. doi: 10.1345/aph.1K516

14. Osborn D, Levy G, Nazareth I, King M (2008) Suicide and severe mental illnesses. Cohort study within the UK general practice research database. Schizophr Res. doi: 10.1016/j.schres.2007.11.025

15. Valuck RJ, Orton HD, Libby AM (2009) Antidepressant discontinuation and risk of suicide attempt: a retrospective, nested case-control study. J Clin Psychiatry. doi: 10.4088/JCP.08m04943 
16. Haukka J, Tiihonen J, Harkanen T, Lonnqvist J (2008) Association between medication and risk of suicide, attempted suicide and death in nationwide cohort of suicidal patients with schizophrenia. Pharmacoepidemiol Drug Saf. doi: 10.1002/pds.1579

17. Tiihonen J, Lonnqvist J, Wahlbeck K, Klaukka T, Tanskanen A, Haukka J (2006) Antidepressants and the risk of suicide, attempted suicide, and overall mortality in a nationwide cohort. Arch Gen Psychiatry. doi:

10.1001/archpsyc.63.12.1358

18. Andersson L (2006) Regional differences in disability pension and sickness absence with psychiatric diagnoses in Sweden and Norway 1980-2000: the influence of demography and access to psychiatric health care. Dissertation or Thesis, The Sahlgrenska Academy at Göteborg University, Department of Public Health and Community Medicine

19. Wettermark B, Hammar N, Fored CM, Leimanis A, Otterblad Olausson P, Bergman U, Persson I, Sundstrom A, Westerholm B, Rosen M (2007) The new Swedish Prescribed Drug Register--opportunities for pharmacoepidemiological research and experience from the first six months. Pharmacoepidemiol Drug Saf. doi: $10.1002 / p d s .1294$

20. Anon (2002) Anatomical Therapeutic Chemical (ATC) Classification Index

21. Act (2002:160) on Pharmaceutical Benefits, etc.(2002)

22. Rosholm JU, Andersen M, Gram LF (2001) Are there differences in the use of selective serotonin reuptake inhibitors and tricyclic antidepressants? A prescription database study. Eur J Clin Pharmacol

23. Rosholm JU, Gram LF, Isacsson G, Hallas J, Bergman U (1997) Changes in the pattern of antidepressant use upon the introduction of the new antidepressants: a prescription database study. Eur J Clin Pharmacol 52:205-9

24. Zito JM, Tobi H, de Jong-van den Berg LT, Fegert JM, Safer DJ, Janhsen K, Hansen DG, Gardner JF, Glaeske G (2006) Antidepressant prevalence for youths: a multi-national comparison. Pharmacoepidemiol Drug Saf. doi: $10.1002 / p d s .1254$

25. Kairuz T, Truter I, Hugo J, Foxcroft C (2003) Prescribing patterns of tricyclic and selective serotonin reuptake inhibitor antidepressants among a sample of adolescents and young adults. Pharmacoepidemiol Drug Saf. doi: 10.1002/pds.854

26. Haukka J, Arffman M, Partonen T, Sihvo S, Elovainio M, Tiihonen J, Lonnqvist J, Keskimaki I (2009) Antidepressant use and mortality in Finland: a register-linkage study from a nationwide cohort. Eur J Clin Pharmacol. doi: 10.1007/s00228-009-0616-9

27. Sondergard L, Kvist K, Andersen PK, Kessing LV (2006) Do antidepressants prevent suicide?. Int Clin Psychopharmacol 21:211-218

28. Sondergard L, Lopez AG, Andersen PK, Kessing LV (2007) Continued antidepressant treatment and suicide in patients with depressive disorder. Arch Suicide Res. doi: 10.1080/13811110701249889

29. Smith EG, Sondergard L, Lopez AG, Andersen PK, Kessing LV (2009) Association between consistent purchase of anticonvulsants or lithium and suicide risk: A longitudinal cohort study from Denmark, 1995-2001. J Affect Disord. doi: 10.1016/j.jad.2009.01.013

30. Sondergard L, Lopez AG, Andersen PK, Kessing LV (2008) Mood-stabilizing pharmacological treatment in bipolar disorders and risk of suicide. Bipolar Disord. doi: 10.1111/j.1399-5618.2008.00464.x 
31. Patorno E, Bohn RL, Wahl PM, Avorn J, Patrick AR, Liu J, Schneeweiss S (2010) Anticonvulsant medications and the risk of suicide, attempted suicide, or violent death. JAMA. doi: 10.1001/jama.2010.410

32. Gardarsdottir H, van Geffen EC, Stolker JJ, Egberts TC, Heerdink ER (2009) Does the length of the first antidepressant treatment episode influence risk and time to a second episode?. J Clin Psychopharmacol. doi: 10.1097/JCP.0b013e31819302b1

33. Gardarsdottir H, Heerdink ER, Egberts AC (2006) Potential bias in pharmacoepidemiological studies due to the length of the drug free period: a study on antidepressant drug use in adults in the Netherlands.

Pharmacoepidemiol Drug Saf. doi: 10.1002/pds.1223

34. Gardarsdottir H, Heerdink ER, van Dijk L, Egberts AC (2007) Indications for antidepressant drug prescribing in general practice in the Netherlands. J Affect Disord. doi: 10.1016/j.jad.2006.07.003

35. Henriksson S, Boethius G, Hakansson J, Isacsson G (2003) Indications for and outcome of antidepressant medication in a general population: a prescription database and medical record study, in Jamtland county, Sweden, 1995. Acta Psychiatr Scand 108:427-431 
Table 1. One-year prevalence of antidepressant use (rate per 100 inhabitants) and proportion of new users by age and sex. Differences in rates per 100 inhabitants between men and women were tested with Pearson's $\chi^{2}$-test, and trend test was used to analyze trends over age groups, $p$-values are presented in the table.

\begin{tabular}{|c|c|c|c|c|c|c|c|c|c|c|c|}
\hline Age & Men & & & & & Women & & & & & $\chi^{2}$ \\
\hline & $\begin{array}{r}\text { All } \\
\text { users }\end{array}$ & Population & $\begin{array}{r}\text { Rate per } \\
100 \\
\text { inhabitants }\end{array}$ & $\begin{array}{c}\text { New } \\
\text { users }^{\text {a }}\end{array}$ & $\begin{array}{r}\text { Proportion } \\
\text { new users }\end{array}$ & All users & Population & $\begin{array}{r}\text { Rate per } \\
100 \\
\text { inhabitants }\end{array}$ & $\begin{array}{r}\text { New } \\
\text { users }^{\text {a }}\end{array}$ & $\begin{array}{r}\text { Proportion } \\
\text { new users } \\
{ }^{\mathrm{a}}(\%)\end{array}$ & $\mathrm{P}$ \\
\hline $20-24$ & 7,907 & 277,497 & 2.8 & 3,993 & 50.5 & 15,276 & 264,080 & 5.8 & 7,034 & 46.0 & $<0.001$ \\
\hline $25-29$ & 11,930 & 279,309 & 4.3 & 5,173 & 43.4 & 19,510 & 268,425 & 7.3 & 7,890 & 40.4 & $<0.001$ \\
\hline
\end{tabular}

${ }^{\text {a }}$ No antidepressant purchase during July - December 2005.

** $\mathrm{p}<0.001$ for trend 
Table 2. Distribution of substances at the first antidepressant purchase for all users in 2006 by sex, expressed as percentage of total number of users (34,472 men and 59,750 women). Substances purchased by less than 100 individuals are included in the 'Others' category. Risk ratios (RR) were calculated to investigate differences between sexes and presented with $95 \%$ confidence intervals $(95 \% \mathrm{Cl})$, women was the reference category.

\begin{tabular}{lrrrrr}
\hline Substance & Men & Women & Total & & \\
& $\mathbf{\%}$ & $\mathbf{\%}$ & $\mathbf{\%}$ & $\mathbf{R R}$ & $\mathbf{9 5 \%} \mathbf{C I}$ \\
\hline Tricyclic antidepressants & 5.9 & 6.7 & 6.4 & 0.87 & $0.83-0.91$ \\
Amitryptiline & 3.8 & 5.1 & 4.6 & 0.74 & $0.69-0.79$ \\
Clomipramine & 1.8 & 1.5 & 1.6 & 1.19 & $1.07-1.31$ \\
Trimipramine & 0.3 & 0.1 & 0.2 & 2.49 & $1.80-3.44$ \\
Selective serotonin re-uptake inhibitors & 71.7 & 78.7 & 76.0 & 0.91 & $0.90-0.92$ \\
Citalopram & 28.0 & 30.0 & 29.3 & 0.93 & $0.91-0.95$ \\
Escitalopram & 7.1 & 6.7 & 6.9 & 1.05 & $1.00-1.10$ \\
Fluoxetine & 6.7 & 11.4 & 9.7 & 0.59 & $0.57-0.62$ \\
Paroxetine & 7.0 & 5.2 & 5.8 & 1.35 & $1.28-1.42$ \\
Sertraline & 22.8 & 25.3 & 24.4 & 0.90 & $0.88-0.93$ \\
Other antidepressants & 22.1 & 14.3 & 17.2 & 1.54 & $1.50-1.59$ \\
Duloxetine & 1.3 & 1.4 & 1.4 & 0.87 & $0.77-0.97$ \\
Mianserin & 0.8 & 0.7 & 0.8 & 1.21 & $1.04-1.41$ \\
Mirtazapine & 11.2 & 5.1 & 7.3 & 2.22 & $2.12-2.32$ \\
Moclobemide & 0.2 & 0.2 & 0.2 & 1.30 & $0.97-1.74$ \\
Reboxetine & 0.6 & 0.3 & 0.4 & 1.90 & $1.55-2.32$ \\
Venlafaxine & 8.2 & 6.8 & 7.3 & 1.21 & $1.15-1.26$ \\
Others & 0.2 & 0.2 & 0.2 & 1.16 & $0.87-1.53$ \\
\hline Total & $\mathbf{1 0 0}$ & $\mathbf{1 0 0}$ & $\mathbf{1 0 0}$ & & \\
\hline & & & & & \\
\hline
\end{tabular}


Table 3. Distribution of number of filled antidepressant prescriptions per individual for new users that purchased their first antidepressant between January and June 2006 ( $n=21,199)$. Risk ratios (RR) were calculated to investigate differences between sexes and presented with $95 \%$ confidence intervals $(95 \% \mathrm{Cl})$, women was the reference category. Differences in mean between sexes were tested with Student's t-test, $p$ value presented in the table.

\begin{tabular}{lrrrrr}
\hline Number of filled prescriptions & $\begin{array}{r}\text { Men } \\
\text { Women }\end{array}$ & Total & RR & $95 \%$ CI \\
& $\%$ & $\%$ & $\%$ & & \\
\hline 1 & 24.1 & 21.4 & 22.4 & 1.12 & $1.07-1.19$ \\
2 & 17.4 & 15.4 & 16.2 & 1.13 & $1.06-1.20$ \\
3 & 15.9 & 16.4 & 16.3 & 0.97 & $0.91-1.03$ \\
4 & 12.8 & 15.7 & 14.7 & 0.82 & $0.76-0.88$ \\
5 or more & 29.6 & 31.1 & 30.7 & 0.96 & $0.92-1.00$ \\
\hline Mean & 3.7 & 3.9 & 3.8 & & P $<0.001$ \\
Median & 3.0 & 3.0 & 3.0 & & \\
\hline
\end{tabular}


Table 4. Proportion of individuals that filled one prescription only for new users by substance and sex $(n=21,199)$. Substances bought by less than 100 individuals have been excluded. Risk ratios (RR) were calculated to investigate differences between sexes and presented with $95 \%$ confidence intervals $(95 \% \mathrm{Cl})$, women was the reference category.

\begin{tabular}{lcllll}
\hline Substance & $\begin{array}{l}\text { Men } \\
\text { Women }\end{array}$ & $\begin{array}{l}\text { RR } \\
\text { 95\% CI }\end{array}$ & $\begin{array}{l}\text { Total } \\
\text { 95 }\end{array}$ \\
\hline Tri-cyclic antidepressants & & & & & \% \\
Amitryptiline & 48.2 & 44.2 & 1.08 & $0.96-1.23$ & 45.4 \\
Clomipramine & 27.5 & 28.6 & 0.96 & $0.61-1.51$ & $28.2^{* *}$ \\
SSRIs & & & & & \\
Citalopram & 22.2 & 20.6 & 1.08 & $0.98-1.18$ & 21.2 \\
Escitalopram & 20.2 & 14.7 & 1.39 & $1.10-1.74$ & 16.9 \\
Fluoxetine & 23.9 & 18.1 & 1.32 & $1.09-1.61$ & 19.6 \\
Paroxetine & 21.3 & 24.1 & 0.96 & $0.76-1.21$ & 23.8 \\
Sertraline & 23.2 & 24.2 & 1.19 & $1.06-1.34$ & 18.5 \\
Other antidepressants & & & & & \\
Duloxetine & 14.0 & 24.2 & 0.58 & $0.38-0.88$ & 20.5 \\
Mianserin & 52.4 & 45.2 & 1.15 & $0.84-1.59$ & $47.9^{* *}$ \\
Mirtazapine & 29.0 & 25.1 & 1.20 & $0.40-3.56$ & 27.4 \\
Venlafaxine & 18.2 & 15.7 & 1.15 & $0.86-1.54$ & 20.6 \\
\hline ** n<150 & & & & &
\end{tabular}


Table 5. Mortality rates by utilization pattern and by sex. Differences in mortality presented as risk ratios with $95 \%$ confidence intervals (RR $(95 \% \mathrm{CI})$ ) for the group in total ( $\mathrm{n}=$ $94,239)$ and by sex. Differences in mortality rate between men and women were analyzed with Pearson's $\chi^{2}$-test, $p$-values are presented in the table.

\begin{tabular}{|c|c|c|c|c|c|c|c|c|c|c|}
\hline \multicolumn{3}{|c|}{ Total } & \multicolumn{3}{|c|}{ Men } & \multicolumn{2}{|r|}{ Women } & & \multicolumn{2}{|r|}{$\begin{array}{l}\text { Between } \\
\text { sex }\end{array}$} \\
\hline & $\begin{array}{r}\text { Mortality } \\
\text { rate } \\
\mathrm{n} / 10,000\end{array}$ & $\mathrm{RR}(95 \% \mathrm{CI})$ & $P$ & $\begin{array}{r}\text { Mortality } \\
\text { rate } \\
\mathrm{n} / 10,000\end{array}$ & $\mathrm{RR}(95 \% \mathrm{CI})$ & $P$ & $\begin{array}{r}\text { Mortality } \\
\text { rate } \\
\mathrm{n} / 10,000\end{array}$ & $\mathrm{RR}(95 \% \mathrm{CI})$ & $P$ & $P$ \\
\hline Non-users & 4.0 & 1.00 & & 5.5 & 1.00 & & 2.4 & 1.00 & & $<0.001$ \\
\hline $\begin{array}{l}\text { All } \\
\text { antidepressant } \\
\text { users }\end{array}$ & 17.6 & $4.39(3.75-5.13)$ & $<0.001^{\mathrm{a}}$ & 23.5 & $4.24(3.42-5.27)$ & $<0.001^{\mathrm{a}}$ & 14.2 & $6.01(4.79-7.53)$ & $<0.001^{\mathrm{a}}$ & 0.009 \\
\hline Prescriptions & 16.5 & 1.00 & & 23.4 & 1.00 & & 12.6 & 1.00 & & $<0.001$ \\
\hline Multi-dose users & 60.0 & $3.42(2.07-5.65)$ & $0.002^{b}$ & 26.3 & $1.12(0.37-3.41)$ & $0.842^{\mathrm{b}}$ & 92.5 & $6.62(3.80-11.52)$ & $<0.001^{\mathrm{b}}$ & 0.037 \\
\hline $\begin{array}{l}\text { Start 2006/new } \\
\text { users }\end{array}$ & 15.7 & 1.00 & & 18.8 & 1.00 & & 13.9 & 1.00 & & 0.229 \\
\hline $\begin{array}{l}\text { Start } 2005 \text { or } \\
\quad \text { earlier }\end{array}$ & 19.0 & $1.08(0.96-1.21)$ & $0.246^{\mathrm{c}}$ & 27.0 & $1.15(0.98-1.35)$ & $0.120^{c}$ & 14.5 & $1.02(0.86-1.21)$ & $0.848^{c}$ & 0.001 \\
\hline \multicolumn{11}{|c|}{ Baseline antidepressant } \\
\hline $\begin{array}{l}\text { Tricyclic } \\
\text { antidepressants }\end{array}$ & 28.1 & $1.30(0.79-2.15)$ & $0.303^{\mathrm{e}}$ & 24.7 & $1.05(0.45-2.45)$ & $0.918^{\mathrm{e}}$ & 29.8 & $1.56(0.84-2.89)$ & $0.164^{\mathrm{e}}$ & 0.725 \\
\hline SSRI & 14.6 & $0.88(0.79-0.98)$ & $0.005^{\mathrm{f}}$ & 18.9 & $0.91(0.78-1.07)$ & $0.207^{\mathrm{f}}$ & 12.3 & $0.87(0.75-1.00)$ & $0.019^{f}$ & 0.028 \\
\hline Citalopram & 11.3 & $0.70(0.52-0.94)$ & 0.012 & 11.9 & $0.66(0.42-1.04)$ & 0.057 & 11.0 & $0.74(0.50-1.11)$ & 0.122 & 0.845 \\
\hline Sertraline & 13.9 & $0.82(0.60-1.11)$ & 0.179 & 20.3 & $0.92(0.60-1.40)$ & 0.695 & 17.2 & $0.75(0.48-1.16)$ & 0.173 & 0.060 \\
\hline $\begin{array}{l}\text { Other } \\
\text { antidepressants }\end{array}$ & 26.3 & $1.40(1.07-1.84)$ & $0.018^{\mathrm{g}}$ & 36.8 & $1.23(0.86-1.76)$ & $0.274^{\mathrm{g}}$ & 17.2 & $1.48(0.98-2.23)$ & $0.072^{\mathrm{g}}$ & 0.011 \\
\hline Mirtazapine & 39.8 & $2.06(1.44-2.96)$ & $<0.001$ & 47.8 & $1.76(1.14-2.74)$ & 0.015 & 29.3 & $2.10(1.13-3.90)$ & 0.020 & 0.221 \\
\hline Venlafaxine & 16.4 & $0.82(0.45-1.50)$ & 0.521 & 26.4 & $0.75(0.32-1.76)$ & 0.504 & 9.3 & $0.86(0.37-2.02)$ & 0.735 & 0.075 \\
\hline \multicolumn{11}{|c|}{ Concurrent use of mood-stabilizing agent } \\
\hline $\begin{array}{l}\text { Any mood- } \\
\text { stabilizing agent }\end{array}$ & 47.6 & $2.93(1.84-4.68)$ & $<0.001^{\mathrm{h}}$ & 53.9 & $2.45(1.23-4.90)$ & $0.009^{h}$ & 43.5 & $3.36(1.79-6.33)$ & $\begin{array}{r}<0.001 \\
\mathrm{~h}\end{array}$ & 0.632 \\
\hline Lithium & 30.2 & $1.71(0.56-5.27)$ & $0.343^{\mathrm{i}}$ & 25.9 & $1.10(0.16-7.75)$ & $0.922^{\mathrm{i}}$ & 30.2 & $2.31(0.59-9.12)$ & $0.221^{\mathrm{i}}$ & 0.846 \\
\hline Other $^{1}$ & 47.8 & $2.72(1.73-4.27)$ & $<0.001^{\mathrm{j}}$ & 57.0 & $2.43(1.26-4.71)$ & $0.008^{\mathrm{j}}$ & 41.8 & $2.95(1.59-5.47)$ & $0.001^{\mathrm{j}}$ & 0.521 \\
\hline \multicolumn{11}{|c|}{ Concurrent use of antipsychotics } \\
\hline $\begin{array}{l}\text { Any } \\
\text { antipsychotic }\end{array}$ & 49.6 & $2.83(2.20-3.63)$ & $<0.001^{\mathrm{k}}$ & 48.2 & $3.61(2.57-5.07)$ & $<0.001^{\mathrm{k}}$ & 51.1 & $2.05(1.42-2.97)$ & $<0.001^{\mathrm{k}}$ & 0.841 \\
\hline
\end{tabular}


agent

New users, baseline January-June 2006, regular prescriptions

More than one

14.5

1.00

11.4

1.00

0.171

prescription

One filled

$35.4 \quad 1.80(1.25-2.61)$

$0.005^{\mathrm{d}}$

$25.8 \quad 1.22(0.58-2.55)$

$0.611^{\mathrm{d}}$

41.8

$2.25(1.49-3.38)$

$0.001^{\mathrm{d}}$

0.362

${ }^{\text {a }}$ All users $(\mathrm{n}=94,239)$ vs. non-users $(\mathrm{n}=1,597,117)$

${ }^{\mathrm{b}}$ Multi-dose users vs. users with prescriptions

${ }^{c}$ Start 2005 or earlier vs. start 2006

${ }^{\mathrm{d}}$ One filled prescription vs. more than one filled prescription

e Tricyclic antidepressant vs. all other antidepressants

${ }^{\mathrm{f}}$ SSRI vs. all other antidepressants

${ }^{\mathrm{g}}$ Baseline antidepressant in the group other antidepressants vs. baseline antidepressant not in the group other antidepressants

${ }^{\mathrm{h}}$ Concurrent use of any mood stabilizer vs. no concurrent use of any mood stabilizer

${ }^{\mathrm{i}}$ Concurrent use of lithium vs. no concurrent use of lithium

${ }^{\mathrm{j}}$ Concurrent use of carbamazepine, lamotrigine or valproic acid vs. no concurrent use of carbamazepine, lamotrigine or valproic acid

${ }^{\mathrm{k}}$ Concurrent use of antipsychotic drugs vs. no concurrent use of antipsychotics

${ }^{1}$ Carbamazepine, lamotrigine or valproic acid 
